\title{
IMPLEMENTASI KENAIKAN TARIF PROGRESIF PADA PETIKEMAS IMPOR DALAM UPAYA MENEKAN DWELLING TIME DI TERMINAL PETIKEMAS KOJA
}

\section{IMPLEMENTATION OF PROGRESSIVEON IMPORTIN EFFORTS TO RATE INCREASINGPETIKEMASIMPRESS DWELLING TIME AT THE KOJA PETIKEMAS TERMINAL}

\author{
a,1* Kencana Verawati, Alisa Yuki Azizah ${ }^{\mathrm{b}, 2}$ \\ a Dosen Pembimbing Prodi D III Transportasi, Jl. Rawamangun Muka, Jakarta Timur, Indonesia \\ ${ }^{\mathrm{b}}$ Mahasiswa Prodi D III Transportasi, Jl. Rawamangun Muka, Jakarta Timur, Indonesia \\ 1* kencanaverawati@unj.ac.id, ${ }^{2}$ alisayuki.9a@gmail.com \\ *corresponding e-mail: transportasiunj@yahoo.co.id
}

\section{ABSTRACT}

This final assignment aims to determine the average dwelling time at Koja Container Terminal from before the progressive tariff increase and after the progressive tariff increase was made. This final project research activity was carried out while carrying out the Field Work Practices at Koja Container Terminal, which is a company in the field of container loading and unloading services. The calculation of the average dwelling time in this study does not include data on containers moved to another stockpile (overbrengen). The high dwelling time makes the port incompatible with its function. Dwelling time consists of three components, namely preclearance, customs clearance, and post-clearance. One of the factors affecting the dwelling time is on the importer because dwelling time tends to be regulated by the sender of the goods in removing the goods from the port. So that service quality is not the only factor that affects dwelling time, but the cost of storing goods at the port also contributes. This progressive tariff increase is expected to restore the port's function as a gate for goods traffic, not as container storage because the port's main business is to accelerate the loading and unloading service process. This policy is also expected to provide a deterrent effect for imported goods owners to immediately remove their goods from the port's first line area.

Keywords : Progressive Tariff, Dwelling Time, Container, Import

\begin{abstract}
ABSTRAK
Penulisan tugas akhir ini bertujuan untuk mengetahui besaran rata-rata dwelling time di Terminal Petikemas Koja dari sebelum kenaikan tarif progresif dan sesudah dilakukannya kenaikan tarif progresif. Kegiatan penelitian tugas akhir ini dilakukan selama melaksanakan Praktik Kerja Lapangan di Terminal Petikemas Koja yang merupakan sebuah perusahaan dibidang jasa pelayanan bongkar muat petikemas. Perhitungan rata-rata dwelling time dalam penelitian ini tidak memasukkan data petikemas yang dipindahkan ke tempat penimbunan lain (overbrengen). Tingginya dwelling time menjadikan pelabuhan tidak sesuai dengan fungsinya.
\end{abstract}


Dwelling time terdiri dari tiga komponen, yaitu pre-clearance, customs clearance, dan postclearance. Salah satu faktor yang mempengaruhi $d$ welling time berada pada importir karena dwelling time cenderung diatur oleh pengirim barang dalam mengeluarkan barangnya dari pelabuhan. Sehingga kualitas layanan bukan menjadi satu-satunya faktor yang mempengaruhi dwelling time, tetapi biaya penyimpanan barang dipelabuhan juga ikut berkontribusi. Kenaikan tarif progresif ini diharapkan dapat mengembalikan fungsi pelabuhan sebagai gerbang lalu lintas barang, bukan sebagai penyimpanan petikemas karena bisnis utama pelabuhan adalah mempercepat proses pelayanan bongkar muat. Kebijakan tersebut diharapkan juga dapat memberikan efek jera bagi pemilik barang impor untuk segera mengeluarkan barangnya dari kawasan lini satu pelabuhan.

Kata kunci : Tarif Progresif, Dwelling Time, Petikemas, Impor

\section{A. Pendahuluan}

Pelabuhan memiliki peranan penting dalam perekonomian negara. Menurut Pasal 1 angka 1 Peraturan Pemerintah No. 69 Tahun 2001 tentang Kepelabuhanan, pelabuhan adalah tempat yang terdiri dari daratan dan perairan disekitarnya dengan batas tertentu sebagai tempat kegiatan pemerintahan dan kegiatan ekonomi yang dipergunakan sebagai tempat kapal bersandar, berlabuh, naik turun penumpang dan/atau bongkar muat barang yang dilengkapi dengan fasilitas keselamatan pelayaran dan kegiatan penunjang pelabuhan serta sebagai tempat perpindahan intra dan antar moda transportasi. Penanganan terhadap perpindahan barang baik yang akan masuk atau keluar dilaksanakan di terminal.

Terminal merupakan unsur utama yang paling penting dari pelabuhan dalam melayani kapal dan melaksanakan bongkar muat barang. Berbagai fasilitas yang dibutuhkan dalam melaksanakan kegiatan bongkar muat barang disesuaikan dengan jenis barang, kemasan barang yang akan ditangani dan jenis kapal yang akan dilayani. Terminal memberikan pelayanan kepada perusahaan pelayaran sebagai operator terminal. Pelayanan yang diberikan berupa kegiatan bongkar muat, menyusun dan menyimpan barang dalam gudang transit atau menyusun barang atau petikemas di lapangan penumpukan, menerima barang yang akan dikapalkan dan menyerahkan barang setelah dibongkar dari kapal.

Di Indonesia kegiatan perekonomian masih terpusat pada Pelabuhan Tanjung Priok. Terminal Petikemas Koja merupakan suatu entitas bisnis di Pelabuhan Tanjung Priok yang melayani proses bongkar muat petikemas baik untuk ekspor maupun impor serta memiliki peran yang strategis terhadap pertumbuhan industri dan perdagangan sekaligus sebagai sektor usaha yang memberikan kontribusi bagi pembangunan nasional, oleh karena itu sudah seharusnya mampu menjamin kelancaran seluruh aktivitas di pelabuhan, namun pelabuhan tidak terlepas dari permasalahan dan tantangan yang harus segera diselesaikan, salah satunya yaitu fenomena dwelling time. Dwelling time atau masa tunggu bongkar muat adalah waktu yang dihitung mulai dari petikemas (container) dibongkar dan diangkat (unloading) dari kapal sampai petikemas tersebut meninggalkan terminal petikemas melalui pintu utama.

Berdasarkan Peraturan Menteri Perhubungan No PM 25 Tahun 2017, yaitu lapangan penumpukan petikemas bukan merupakan tempat penimbunan barang tetapi sebagai area transit 
untuk menunggu pemuatan atau pengeluarannya, maka fungsi pelabuhan pada dasarnya adalah sebagai area transit petikemas. Namun saat ini masih banyak petikemas yang mengendap di lapangan penumpukan lini satu menjadikan fungsi pelabuhan tidak seusai dengan peruntukannya. Hal ini dikarenakan pemilik barang tidak segera melakukan kepengurusan petikemasnya padahal petikemas tersebut telah memiliki izin untuk dikeluarkan dari terminal. Import container dwelling time memegang peranan penting karena berhubungan langsung dengan lama waktu yang harus dilalui dalam satu rangkaian proses pelayanan kepengurusan petikemas di dalam terminal. Apabila permasalahan tersebut tidak segera diberikan langkah perbaikan maka akan sangat berdampak terhadap kelancaran kegiatan di lingkungan pelabuhan.

Dalam beberapa tahun terakhir penurunan waktu dwelling time impor menjadi fokus utama dan menjadi salah satu prioritas kinerja pemerintah yang bertujuan untuk menekan biaya logistik serta kelancaran arus barang di pelabuhan. Untuk mengakomodir kebutuhan akan kelancaran bongkar muat barang, sebagai operator Pelabuhan Tanjung Priok, PT Pelabuhan Indonesia II (Persero) atau Pelindo II terus berupaya dalam menekan dwelling time, maka pada tahun 2016 Kementrian Perhubungan menaikkan tarif progresif.

Kenaikan tarif progresif ini diharapkan dapat mendorong importir untuk segera menyelesaikan kepengurusan petikemasnya supaya tidak berlama-lama menimbun petikemas dilapangan penumpukan lini satu. Penaikan tarif progresif juga diharapkan dapat mengembalikan fungsi pelabuhan sebagai area transit barang, bukan sebagai penyimpanan petikemas karena bisnis utama pelabuhan adalah mempercepat proses pelayanan bongkar muat. Tarif progresif merupakan penetapan tarif menurut dimensi waktu, jika semakin lama menggunakan layanan jasa tersebut maka biaya yang dibayarkan juga akan semakin besar. Tarif progresif bersifat maju, meningkat, meluas, berkelanjutan atau bertahap selama periode waktu tertentu baik secara kuantitatif ataupun kualitatif.

Dwelling Time adalah waktu yang dibutuhkan suatu container impor sejak container dibongkar (unloading) dari atas kapal sampai petikemas tersebut meninggalkan kawasan terminal melalui pintu utama (gate out). Definisi tentang dwelling time ini serupa dengan konsep yang digunakan oleh Dirjen Bea dan Cukai, yaitu :

1. Pre-clearance (waktu kepengurusan dokumen) dari mulai :

a. Petikemas (container) dibongkar dan diangkat dari kapal

b. Petikemas diletakkan di tempat penimbunan sementara (TPS)

c. Penyiapan dokumen Pemberitahuan Impor Barang (PIB)

2. Customs clearance (pemeriksaan Bea Cukai) dari mulai :

a. Pemeriksaan fisik petikemas (khusus untuk jalur merah)

b. Verifikasi dokumen-dokumen oleh Bea Cukai

c. Pengeluaran Surat Persetujuan Pengeluaran Barang (SPPB)

3. Post-clearance (pengeluaran petikemas) dari mulai :

a. Petikemas (container) diangkut keluar kawasan pelabuhan

b. Pemilik Petikemas melakukan pembayaran ke operator pelabuhan 
maka dwelling time impor dapat dihitung sebagai berikut :

$\mathrm{DT}=\mathrm{TP}+\mathrm{TCC}+\mathrm{TPC}$

$\mathrm{DT}=$ dwelling time impor

$\mathrm{TP}=$ Lama waktu pre-clearance

TCC = Lama waktu customs clearance

TPC = Lama waktu post-clearance

\section{B. Metode Penelitian}

Dalam penelitian ini, pengumpulan data diperoleh dengan cara melakukan pengamatan secara langsung selama melaksanakan Praktik Kerja Lapangan di Terminal Petikemas Koja untuk menyajikan gambaran lengkap mengenai "Implementasi Kenaikan Tarif Progresif pada Petikemas Impor Dalam Upaya Menekan Dwelling Time di Terminal Petikemas Koja”.

\section{Hasil dan Pembahasan}

Kenaikan tarif progresif di pelabuhan sebagai upaya untuk menurunkan waktu inap barang hingga keluar pelabuhan yang biasa disebut dengan waktu dwelling time. Sebelum dilakukan perubahan tarif progresif pada tanggal 1 maret 2016. Perubahan tarif ini bukan merubah tarif dasar tetapi hanya merubah tarif pinalti. Tarif dasar untuk petikemas isi impor 20 feet sebesar Rp. 27.200 dan untuk petikemas isi impor 40 feet sebesar Rp. 54.400. Pemberlakuan tarif ini hanya diberlakukan di empat pelabuhan, yaitu Pelabuhan Belawan (Medan), Pelabuhan Makassar, Pelabuhan Tanjung Perak (Surabaya) dan Pelabuhan Tanjung Priok (Jakarta).

Kenaikan tarif progresif ini bertujuan agar barang yang menumpuk dipelabuhan tidak lebih dari tiga hari seperti aturan pemerintah dalam Permenhub No. 117 tahun 2015 tentang Pemindahan Barang yang Melewati Batas Waktu Penumpukan (Long Stay) di Pelabuhan Tanjung Priok. Adapun tarif yang digunakan sebelum kenaikan tarif progresif tersebut disajikan pada Tabel 1.

Tabel 1. Tarif Progresif Sebelum Kenaikan

\begin{tabular}{|l|c|c|}
\hline \multicolumn{1}{|c|}{ Tarif Dasar (TD) } & Petikemas 20' & Petikemas 40' \\
\cline { 2 - 3 } & Rp. 27.200 & Rp. 54.400 \\
\hline Masa bebas (hari ke 1 - 3) & Free & Free \\
\hline Masa I (hari ke 4 - 10) & $500 \%$ x TD & $500 \%$ x TD \\
\hline Masa II (hari ke 11 - dst) & $750 \%$ X TD & $750 \%$ X TD \\
\hline
\end{tabular}

Penerapan tarif tersebut dinilai belum efektif dalam menurunkan $d$ welling time karena dinilai masih tergolong cukup murah. Tarif tersebut belum bisa memberikan efek jera kepada para importir karena masih banyak yang menimbun barangnya dipelabuhan. Sehingga pemerintah menaikkan tarif progresif pada bulan Maret 2016. Kenaikan tarif ini dilakukan agar para pelaku usaha tidak menimbun barangnya dipelabuhan lebih dari 3 (tiga) hari sesuai dengan 
aturan Permenhub No. 117 tahun 2015. Adapun tarif progresif untuk impor yang dikenakan pada tanggal 1 Maret 2016 disajikan pada Tabel 2.

Tabel 2. Kenaikan Tarif Progresif pada 1 Maret 2016

\begin{tabular}{|l|c|c|}
\hline \multirow{2}{*}{ Tarif Dasar (TD) } & Petikemas 20' & Petikemas 40' \\
\cline { 2 - 3 } & Rp. 27.200 & Rp. 54.400 \\
\hline Masa bebas (1 hari) & Free & Free \\
\hline Masa II (hari ke-2 dst) & $900 \%$ x TD & $900 \%$ x TD \\
\hline
\end{tabular}

Perubahan tarif tersebut dinilai sangat tinggi oleh Asosiasi Logistik Indonesia sehingga memberatkan para pelaku usaha dibandingkan dengan tarif sebelumnya tetapi hal ini dapat merubah perilaku importir agar segera mengeluarkan barangnya dari pelabuhan atau sebagai shock therapy. Namun, mendapat banyak protes dan menolak pemberlakuan tarif tersebut karena hanya membebaskan tarif penumpukan petikemas pada hari pertama saja, untuk hari kedua dan seterusnya terjadi kenaikan tarif perhari sebesar $900 \%$ dari tarif dasar. Kemudian di ubahlah tarif tersebut. Terhitung mulai tanggal 30 April 2016 mulai dikenakan tarif terbaru yang disajikan pada Tabel 3.

Tabel 3. Kenaikan Tarif Progresif pada 30 April 2016 - Sekarang

\begin{tabular}{|l|c|c|}
\hline \multirow{2}{*}{ Tarif Dasar (TD) } & Petikemas 20' & Petikemas 40' \\
\cline { 2 - 3 } & Rp. 27.200 & Rp. 54.400 \\
\hline Masa bebas (hari ke-1) & Free & Free \\
\hline Masa I (hari ke-2) & $300 \%$ x TD & $300 \%$ x TD \\
\hline Masa II (hari ke-3) & $600 \%$ X TD & $600 \%$ X TD \\
\hline Masa III (hari ke-4 dst) & $900 \%$ x TD & $900 \%$ X TD \\
\hline
\end{tabular}

Berikut sampel percobaan perhitungan tarif mulai dari sebelum kenaikan tarif progresif sampai dengan pergantian tarif progresif :

Sebuah container import standard 1x20 feet ditumpuk di lapangan penumpukan selama 4 (empat) hari, berapa total biaya yang harus dibayarkan?

Diketahui : Tarif Dasar Container Import Standard $20 \mathrm{ft}=\mathrm{Rp} 27.200$

1. Sebelum kenaikan tarif progresif
a. Hari ke satu - ke tiga
$=$ Free
b. Hari ke empat
$=500 \% \times \operatorname{Rp} 27.200$
$=\operatorname{Rp} 136.000$

Total yang harus dibayarkan adalah $\mathrm{Rp} 136.000$

2. Kenaikan tarif progresif $900 \%$
a. Hari pertama
$=$ Free
b. Hari kedua
$=3 \times(900 \% \times \operatorname{Rp} 27.200)$ 


$$
=\operatorname{Rp} 734.400
$$

Total yang harus dibayarkan adalah Rp 734.400

3. Kenaikan tarif progresif $300 \%, 600 \%$, dan $900 \%$
a. Hari pertama
$=$ Free
b. Hari kedua
$=300 \% \times \mathrm{Rp} 27.200$
c. Hari ketiga
$=\operatorname{Rp} 81.600$
$=600 \% \times 27.200$
d. Hari ke empat
$=\operatorname{Rp} 163.200$
$=900 \% \times \mathrm{Rp} 27.200$
$=\operatorname{Rp} 244.800$

Total yang harus dibayarkan adalah Rp 489.600

Dari percobaan diatas maka dapat disimpulkan kenaikan tarif yang terjadi disajikan pada tabel 4.

Tabel 4. Presentase biaya yang dikeluarkan

\begin{tabular}{|l|l|l|l|}
\hline No. & Tarif & $\begin{array}{l}\text { Biaya yang } \\
\text { dikeluarkan }\end{array}$ & $\begin{array}{l}\text { Presentase Kenaikan } \\
\text { dan Penurunan }\end{array}$ \\
\hline 1. & $\begin{array}{l}\text { Sebelum kenaikan tarif } \\
\text { progresif }\end{array}$ & Rp 136.000 & $\begin{array}{l}\text { Kenaikan sebesar } \\
440 \%\end{array}$ \\
\cline { 1 - 2 } 2. & Tarif progresif 900\% & Rp 734.400 & Penurunan sebesar \\
\cline { 2 - 3 } 3. & $\begin{array}{l}\text { Tarif progresif 300\%, } \\
600 \%, 900 \%\end{array}$ & Rp 489.600 & \\
\hline
\end{tabular}

Berdasarkan tabel 4 diatas, jumlah presentase kenaikan tarif progresif (tarif 900\%) meningkat sebanyak $440 \%$. Kenaikan tarif progresif $900 \%$ dinilai dapat mengubah perilaku para importir untuk segera mengeluarkan barangnya dari pelabuhan agar biaya lapangan penumpukan yang dikeluarkan tidak semakin tinggi. Sedangkan pada tarif progresif dengan kelipatan 300\%, $600 \%$, dan $900 \%$ terjadi penurunan sebesar $33 \%$. Kenaikan tarif progresif yang kedua ini tidak terlalu berpengaruh tetapi dapat menstabilkan dwelling time di Terminal Petikemas Koja. Tarif ini juga dirasa cukup adil sehingga tidak memberatkan pihak importir apabila dibandingkan dengan tarif progresif $900 \%$ sebelumnya.

Dari hasil analisis tersebut, kenaikan tarif progresif berpengaruh dalam menekan dwelling time di Terminal Petikemas Koja. Dapat dilihat pada Gambar 1. 


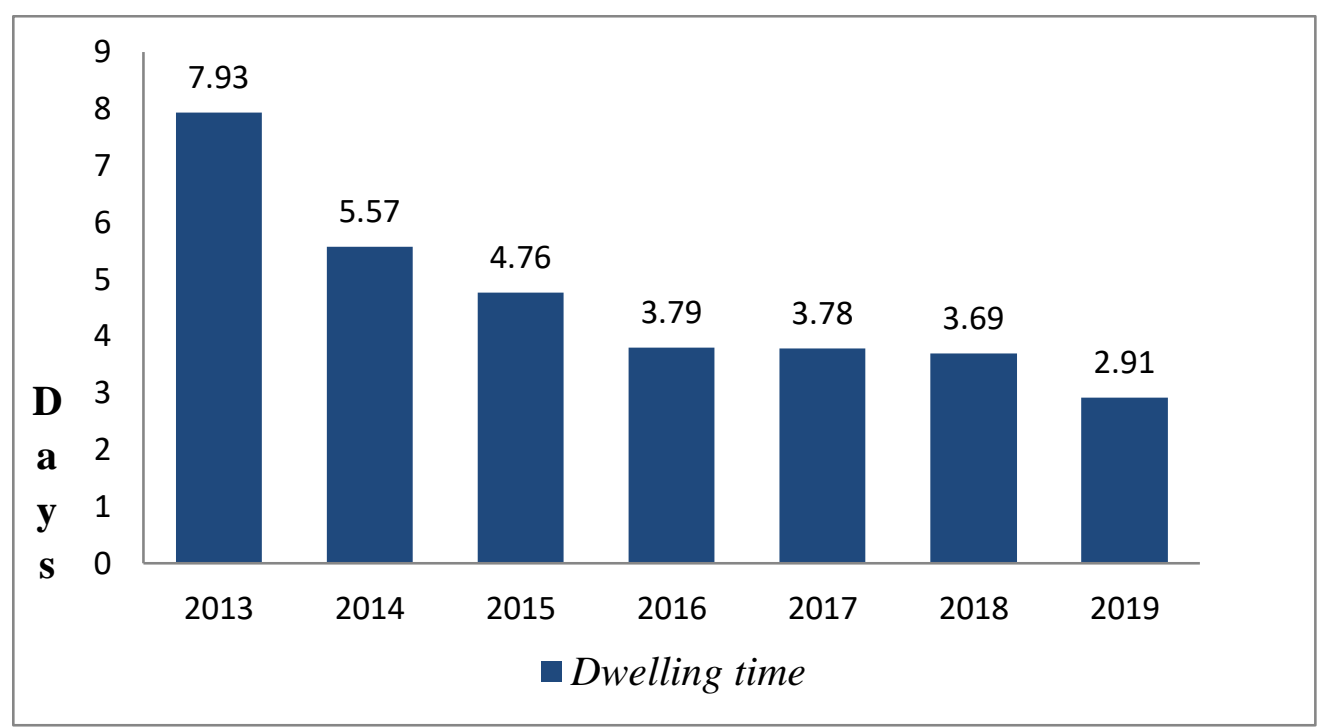

Gambar 1. Grafik Dwelling Time tahun 2013-2019 di TPK Koja

Dari grafik 1 diatas dapat dilihat $d$ welling time sebelum kenaikan tarif dan sesudah kenaikan tarif progresif yang dimulai pada tahun 2016 oleh pemerintah. Angka dwelling time sebelum kenaikan tarif progresif pada tahun 2013 masih diatas 7 hari, tahun 2014 mencapai 5,57 hari, dan tahun 2015 sebesar 4,76 hari. Sejak kenaikan tarif progresif pada tahun 2016, grafik dwelling time di Terminal Petikemas Koja selalu mengalami penurunan sampai dengan tahun 2019 hingga mencapai angka dibawah 3 hari sesuai dengan Permenhub No.117 Tahun 2015 tentang Pemindahan Barang yang Melewati Batas Waktu Penumpukan (Long Stay) di Pelabuhan Tanjung Priok. Jadi, dapat diketahui bahwa kenaikan tarif progresif ini terbukti efektif dalam menekan dwelling time di Terminal Petikemas Koja. Namun masih terdapat beberapa importir yang menumpuk barangnya dipelabuhan.

\section{Simpulan}

Dari berbagai pembahasan dan uraian yang telah dikemukakan diatas, penulis dapat menulis beberapa kesimpulan, antara lain sebagai berikut :

1. Besarnya dwelling time di Terminal Petikemas Koja pada tahun 2019 sebesar 2,91 hari sudah lebih baik sejak kenaikan tarif progresif dibandingkan dengan tahun sebelumnya dan dinyatakan telah mencapai tolak ukur tingkat pelayanan dipelabuhan, yaitu tidak lebih dari 3 hari sesuai dengan aturan Permenhub No. 117 tahun 2015 tentang Pemindahan Barang yang Melewati Batas Waktu Penumpukan (Long Stay) di Pelabuhan Tanjung Priok.

2. Dwelling time terdiri dari tiga komponen, yaitu pre-clearance, customs clearance dan post-clearance. Salah satu faktor yang mempengaruhi lamanya dwelling time impor, yaitu karena pemilik barang/importir tidak segera mengeluarkan barangnya dari pelabuhan. Oleh karena itu pada tahun 2016, pemerintah menaikkan tarif progresif. Dengan kenaikan tarif progresif ini, kecenderungan para pemilik barang impor lebih cepat memproses dokumen pengeluaran barangnya.

3. Kenaikan tarif progresif di Terminal Petikemas Koja terbukti efektif dalam menekan dwelling time karena dapat dilihat dari sebelum kenaikan tarif progresif pada tahun 2013 
- 2015, besarnya dwelling time masih terbilang cukup tinggi sedangkan sejak kenaikan tarif progresif pada tahun 2016, dwelling time selalu mengalami penurunan yang signifikan hingga mencapai 2,91 hari di tahun 2019.

\section{E. Daftar Pustaka}

ARTAKUSUMA, A. (2012). Analisis Import Container Dwelling Time di Pelabuhan

Petikemas Jakarta International Container Terminal (JICT) Tanjung Priok. Bandung : ITB.

Karsafman, Tjeptjep. 2004. Pengenalan Terminal Khusus Curah dan Pengenalannya.

Drs. Achmad Ridwan Tentowi. (2016). Politik Hukum Tata Kelola Kepelabuhanan Nasional Studi Kasus Dwelling Time di Tanjung Priok, Jakarta Utara. Bandung : CV.Warta Bagja.

Hary Purwoko, A.M. (2019). Import Clearance Planning Study at Tanjung Priok Port,

Jakarta. Institut Transportasi dan Logistik Trisakti

Rafi, Salahudin, Budi Purwanto. (2016). Dwelling Time Management (Antara Harapan dan Kenyataan di Indonesia). Jurnal Manajemen Bisnis Transportasi Dan Logistik : STMT Trisakti.

Sherly Luthfi Anita, Indra Asmadewa (2016) Analisis Dwelling Time Impor Pada Pelabuhan Tanjung Priok Melalui Penerapan Theory Of Constraints. Tanggerang: PKN STAN.

Sumardi, dkk. (2010). Manajemen Kepelabuhanan. PT. (PERSERO) Pelabuhan Indonesia: Jakarta.

Sasono, Herman Budi. (2012). Manajemen Pelabuhan dan Ralisasi Ekspor Impor. CV. Andi Offset : Yogyakarta. 